\author{
Рыкова Инна Николаевна, Табуров Денис Юрьевич
}

\title{
ТАРИФНАЯ ПОЛИТИКА НА ОСНОВЕ АНАЛИЗА ДИНАМИКИ РЕГУЛИРУЕМЫХ И СВОБОДНЫХ ЦЕН В ОТРАСЛИ ЭЛЕКТРОЭНЕРГЕТИКИ
}

В раиках данной статьи проведен анализ: действующей государственной тарифной политики в сфере электроэнергетики и новых подходов к ее совериенствованию в целях раскрытия потенциала роста отрасли; динамики регулируемых и свободных уен в отрасли электроэнергетики в Российской Федерачии и в разрезе федеральных округов; влияния перекрестного субсидирования в электроэнергетике на тарифы, рассмотрены основные направления совершенствования государственной тарифной политики в отрасли электроэнергетики в челях улучшения механизмов регулирования и раскрытия потенциала роста отрасли.

Ключевые слова: тарифная политика, электроэнергетика, реальный сектор экономики, регулируемые, свободные иены.

Inna Rykova, Denis Taburov

\section{TARIFF POLICY BASED ON THE ANALYSIS OF THE DYNAMICS OF REGULATED AND FREE PRICES IN THE ELECTRICITY SECTOR}

Within the framework of this article the analysis of the current state tariff policy in the field of electricity and new approaches to its improvement in order to unlock the grow th potential of the industry; the analysis of the dynamics of regulated and free prices in the power industry in the Russian Federation and in the context of Federal districts; the analysis of the impact of cross-subsidization in the power industry on tariffs is carried out and the main directions of improvement of the state tariff policy in the power industry in order to improve the mechanisms of regulation and disclosure of the growth potential of the industry are considered.

Key words: tariff policy, power industry, real sector of economy, regulated, free prices.

Подходы к формированию государственной тарифной политики в области электроэнергетики. Стратегическим документом развития отрасли электроэнергетики является Энергетическая стратегия России до 2030 года, при этом основополагающими вехами развития являются возможность инновационного развития отрасли, переформатирование производимых энергоресурсов с учетом выхода на конкурентные позиции в мировой энергетической системе. Приоритетами государственной политика развития отрасли элетроэнергетики являются вопросы энергетической и экологической безопасности, энергетической и бюджетной эффективности.

Следует отметить, что под бюджетной эффективностью энергетики в Стратегии понимается «сбалансированность, устойчивость и предсказуемость, с одной стороны, процессов формирования доходной части бюджета за счет прямых поступлений от хозяйствующих субъектов энергетического сектора, с другой стороны, процессов формирования указанными субъектами инвестиций, необходимых для развития энергетического сектора в целях удовлетворения спроса на энергоресурсы и обеспечения экономически эффективного функционирования» ${ }^{1}$.

Энергетическая стратегия России на период до 2030 года, утвержденной распоряжением Правительства Российской Федерации от 13 нояб̄ря 2009 г. № 1715 -р 
Для достижения поставленных целей по обеспечению бюджетной эффективности энергетики предполагается использовать различные меры государственной энергетической политики, одной из которых является создание благоприятной экономической среды, а именно:

- оптимизация налоговой нагрузки отрасли и налоговых инструментов (например, амортизационная политика);

- совершенствование инвестиционного климата, направленного на соблюдение прав и защиту инвесторов, а также развитие конкурентной среды;

- $\quad$ формирование новых подходов к тарифному регулированию государства, направленного на повышение открытости и прозрачности в области закупок, расширение инвестиционных ресурсов для модернизации отрасли и др.

В целях исследования под государственной тарифной (ценовой) политикой в области электроэнергетики понимается комплекс регулирующих мероприятий по производству, передаче и распределению энергии, направленных на формирование ценовой (тарифной) политики в целях установления справедливого распределения затрат и соблюдения интересов производителей и различных категорий потребителей электроэнергии, а также направленных на стимулирование дальнейшего успешного развития отрасли, создание благоприятной конкурентной среды, внедрение энергосберегающих механизмов, смягчение последствий влияния на окружающую среду.

Динамика регулируемых и свободных цен в отрасли электроэнергетики. В 2017 году общий объем произведенной в Российской Федерации электроэнергии составил 1094288 млн кВт час, что на 3155,1 ед. больше, чем в 2016 году. В тройку лидеров по общему объему производства электроэнергии в 2017 году вошли Центральный федеральный округ; Сибирский федеральный округ и Уральский федеральный округ. Наименьший объем электроэнергии был произведен в Северо-Кавказском федеральном; Дальневосточном федеральном и Южном федеральном округах. На рис. 1 приведены в динамике данные по электробалансу России в 2008-2017 гг. в разрезе федеральных округов. По Российской Федерации производство электроэнергии в 2017 году увеличилось по сравнению с началом рассматриваемого периода (2008 год) на 53909 млн кВт час, при этом динамика данного показателя демонстрировала волнообразный тренд в течение всего периода анализа (2008-2017 гг.) Наименьшее значение анализируемого показателя было зафиксировано в 2009 году и составило 991 979,5 млн кВт час, наибольшее - в 2017 году.

Необходимо отметить, что в целом во всех федеральных округах наблюдался волнообразный тренд показателя производства электроэнергии в 2008-2017 гг. аналогично общей тенденции по РФ.

Общий объем потребленной в Российской Федерации электроэнергии в 2017 году составил 1089 104,7 млн кВт час, что на 11 156,3 больше, чем в 2016 году. В тройку лидеров по потреблению электроэнергии в 2017 году вошли: Центральный федеральный округ (общий объем потребленной электроэнергии в 2017 году составил 225 090,2 млн кВт час, что на 5 480,6 больше, чем в 2016 году); Сибирский федеральный округ (общий объем потребленной электроэнергии в 2017 году составил 221548,6 млн кВт час, что на 213 меньше, чем в 2016 году); Приволжский федеральный округ (общий объем произведенной электроэнергии в 2017 году составил 201 021,4 млн кВт час, что на 3550,0 час больше, чем в 2016 году).

Наименьшее по объемам потребление электроэнергии было отмечено в 2017 году в Северо-Кавказском федеральном округе (общий объем потребленной электроэнергии в 2017 году составил 24 673,5 млн кВт час, что на 30,5 меньше, чем в 2016 году); Дальневосточном федеральном округе (общий объем потребленной электроэнергии в 2017 году составил 48 688,9 млн кВт час, что на 221,7 больше, чем в 2016 году) и Южном федеральном округе (общий объем потребленной электроэнергии в 2017 году составил 68 740,5 млн кВт час, что на 670,3 млн кВт час меньше, чем в 2016 году). 


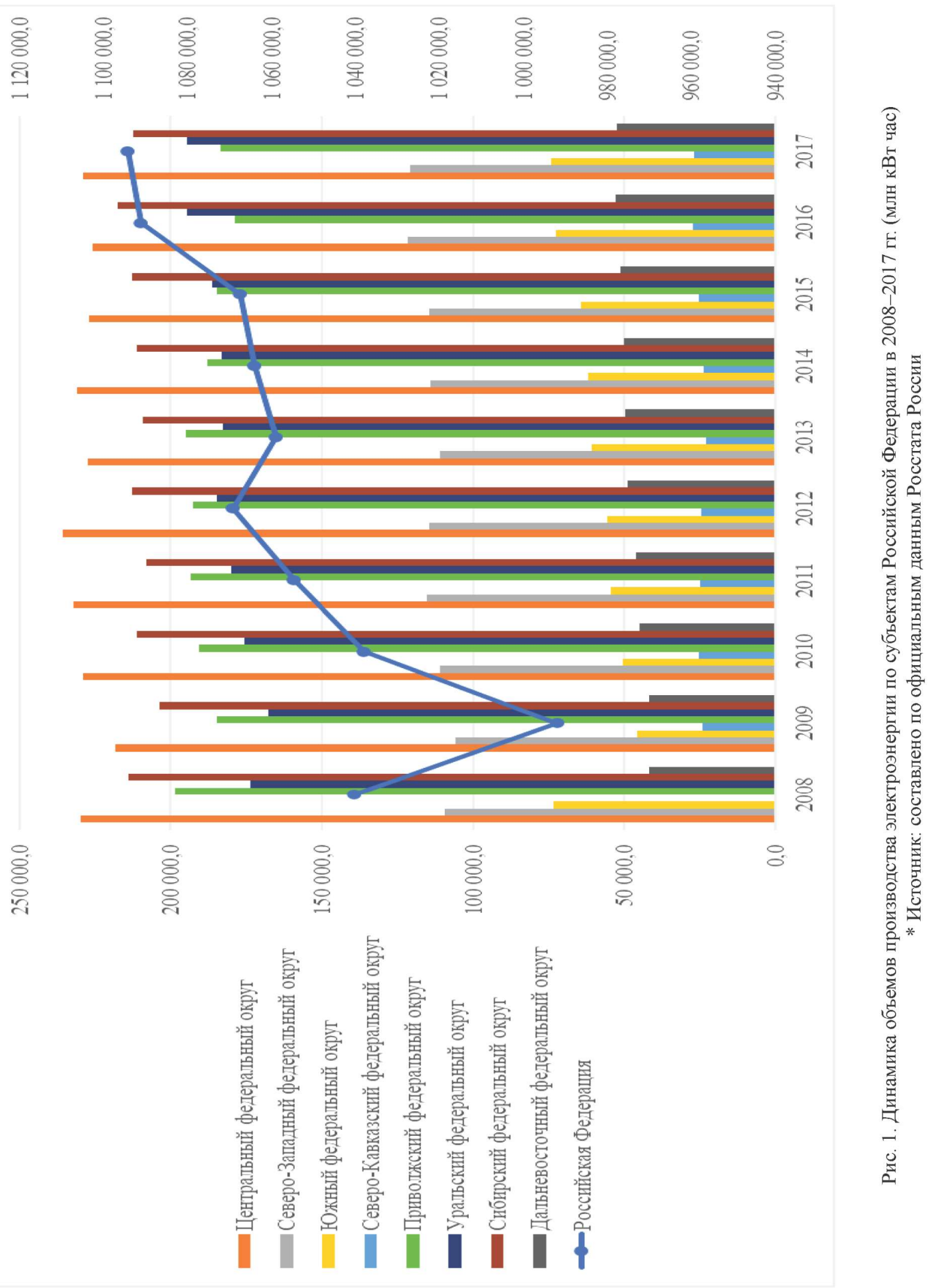



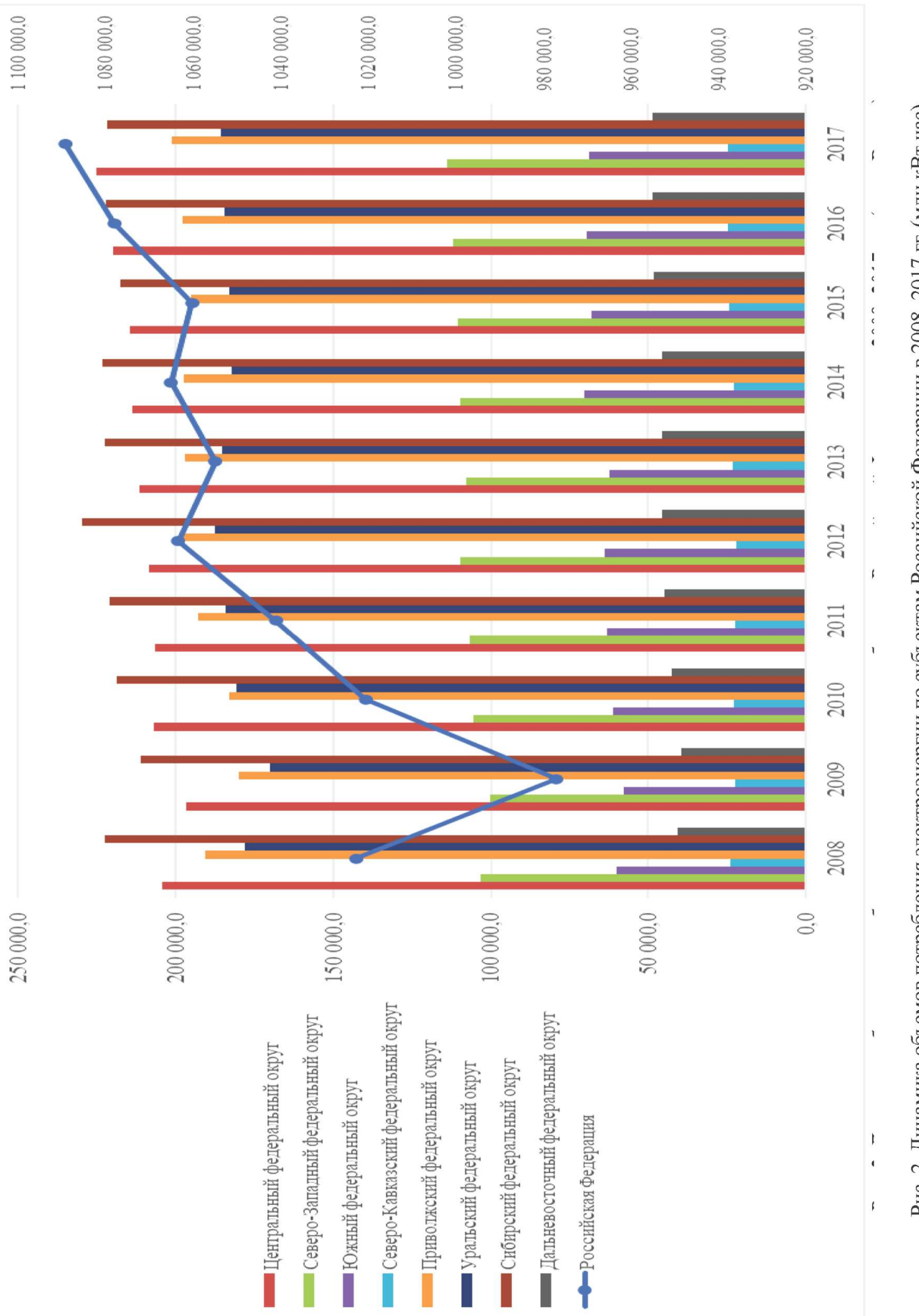
По Российской Федерации потребление электроэнергии в 2017 году увеличилось по сравнению с началом рассматриваемого периода (2008 год) на 66358,5 млн кВт час. При этом динамика данного показателя демонстрировала волнообразный тренд в течение всего периода анализа (2008-2017 гг.) Наименьшее значение анализируемого показателя было зафиксировано в 2009 году и составило 977122,4 млн кВт час, наибольшее - отмечено в 2017 году. При этом больше всего сократилось потребление электроэнергии на конец отчетного периода (2017 год) по сравнению с началом анализируемого периода (2008 год) в Сибирском федеральном округе - снижение объемов потребления электроэнергии составило 601,3 млн кВт час. Волнообразный тренд показателя потребление электроэнергии в 2008-2017 гг. наблюдался во всех федеральных округах, аналогично общей тенденции по РФ.

К категориям потребителей с наименьшими объемами потребления электроэнергии в 2017 году относятся:

- потребители в области информации и связи - 6186 млн кВт час;

- потребители в области строительства - 12 711,1 млн кВт час;

- потребители в сфере сельского хозяйства, охоты и лесного хозяйства - 18 171,1 млн кВт час.

Следует отметить, что наибольший прирост потребления электроэнергии на конец анализируемого периода (2017 год) по сравнению с началом отчетного периода (2008 год) был зафиксирован у следующих категорий потребителей:

- городское и сельское население - прирост объемов потребления на конец отчетного периода по сравнению с началом отчетного периода составил 38 535,0 млн кВт час;

- $\quad$ в сфере добычи полезных ископаемых, обрабатывающих производств, производства и распределения электроэнергии, газа и воды - 10 199,4 млн кВт час;

- в сфере сельского хозяйства, охоты и лесного хозяйства - 2647 млн кВт час.

Значительное сокращение объемов потребления электроэнергии в целом за 2008-2017 гг. было отмечено у потребителей, относящихся к категории «другие виды экономической деятельности» - снижение составило 20 665,9 млн кВт час.

Объемы потери электроэнергии в сетях в 2017 году составили 105 260,9 млн кВт час, уменьшившись по сравнению с 2016 годом на 1985,9 млн кВт час и по сравнению с 2008 годом на 3 979,1 млн кВт час.

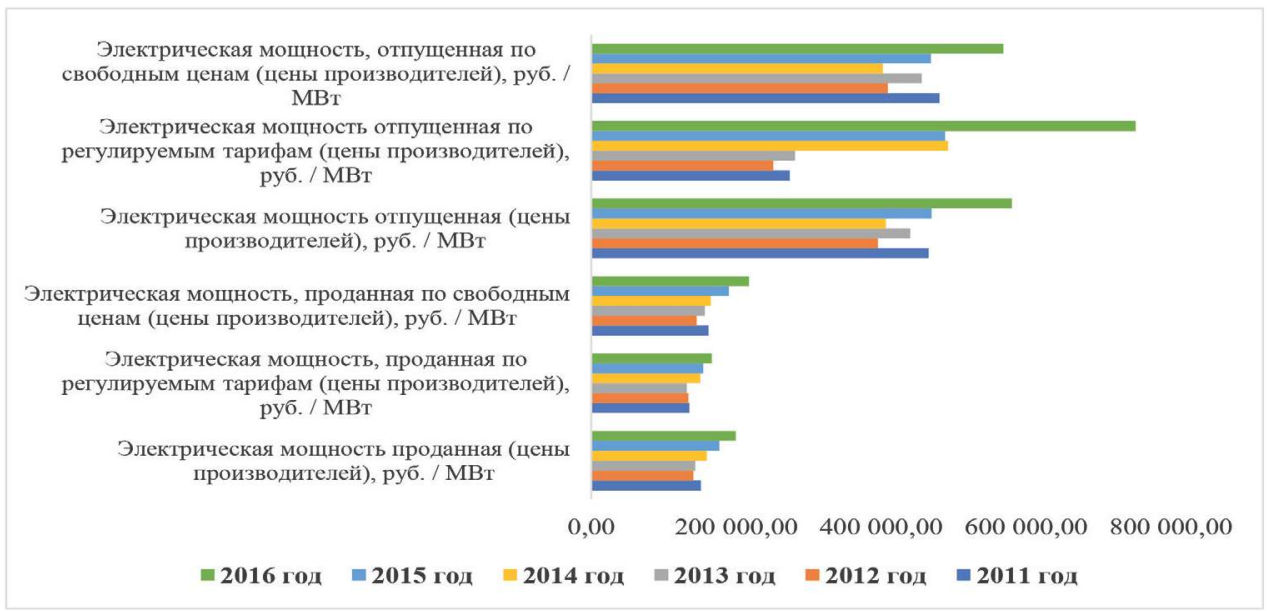

Рис. 3. Показатели реализованных электромощностей в Российской Федерации * Источник: составлено по данным FIRA

В 2016 году цена производителей на проданную электрическую мощность составила 199 153,6 руб./МВт в целом по Российской Федерации, что на 22 509,5 руб./МВт больше, чем в 2015 году. При этом цена производителей на электрическую проданную по регулируемым тари- 
фам мощность составляла в 2016 году 165910,7 руб./МВт (прирост цены по сравнению с предыдущим годом составил 11 364,1 руб./МВт), по свободным ценам - 217 446,1 руб./МВт (прирост цены по сравнению с предыдущим годом составил 27 513,1 руб./МВт). В течение 2011-2016 гг. наблюдался рост цен производителей на электрическую мощность, проданную как по регулируемым тарифам (прирост цены в 2016 году по сравнению с началом анализируемого периода (2011 год) составил 30611,5 руб./МВт, или на $22,6 \%$ ), так и по свободным ценам (прирост цены в 2016 году по сравнению с началом анализируемого периода (2011 год) составил 55 656,0 руб./МВт, или на 34,4 \%). При этом цена производителей на электрическую мощность, проданную по свободным ценам, демонстрирует более быструю динамику роста.

В 2016 году цена производителей на электрическую мощность отпущенную составила 580154,2 руб./МВт в целом по Российской Федерации, что на 110580,1 руб./МВт больше, чем в 2015 году. При этом цена производителей на электрическую мощность отпущенную по регулируемым тарифам составляла в 2016 году 751 242,4 руб./МВт (прирост цены по сравнению с предыдущим годом составил 262 967,2 руб./МВт), по свободным ценам - 568 532,2 руб./МВт (прирост цены по сравнению с предыдущим годом составил 100 117,3 руб./МВт).

Следует отметить, что в течение 2011-2016 гг. наблюдался волнообразный тренд динамики цен производителей на электрическую мощность, отпущенную как по регулируемым тарифам, так и по свободным ценам. Наименьшая цена производителей по регулируемым тарифам на отпущенную электрическую мощность была зафиксирована в 2012 году (250 981,5 руб./МВт), максимальная - в 2016 году (751 242,4 руб./МВт). В целом прирост цены по регулируемым тарифам на электрическую мощность, отпущенную на конец отчетного периода (2016 год), по сравнению с началом рассматриваемого периода (2011 год) составил 477415,8 руб./МВт или на $174,35 \%$; прирост цены на электрическую мощность отпущенную по свободным ценам составил 87 924,3 руб./МВт или на $18,29 \%$.

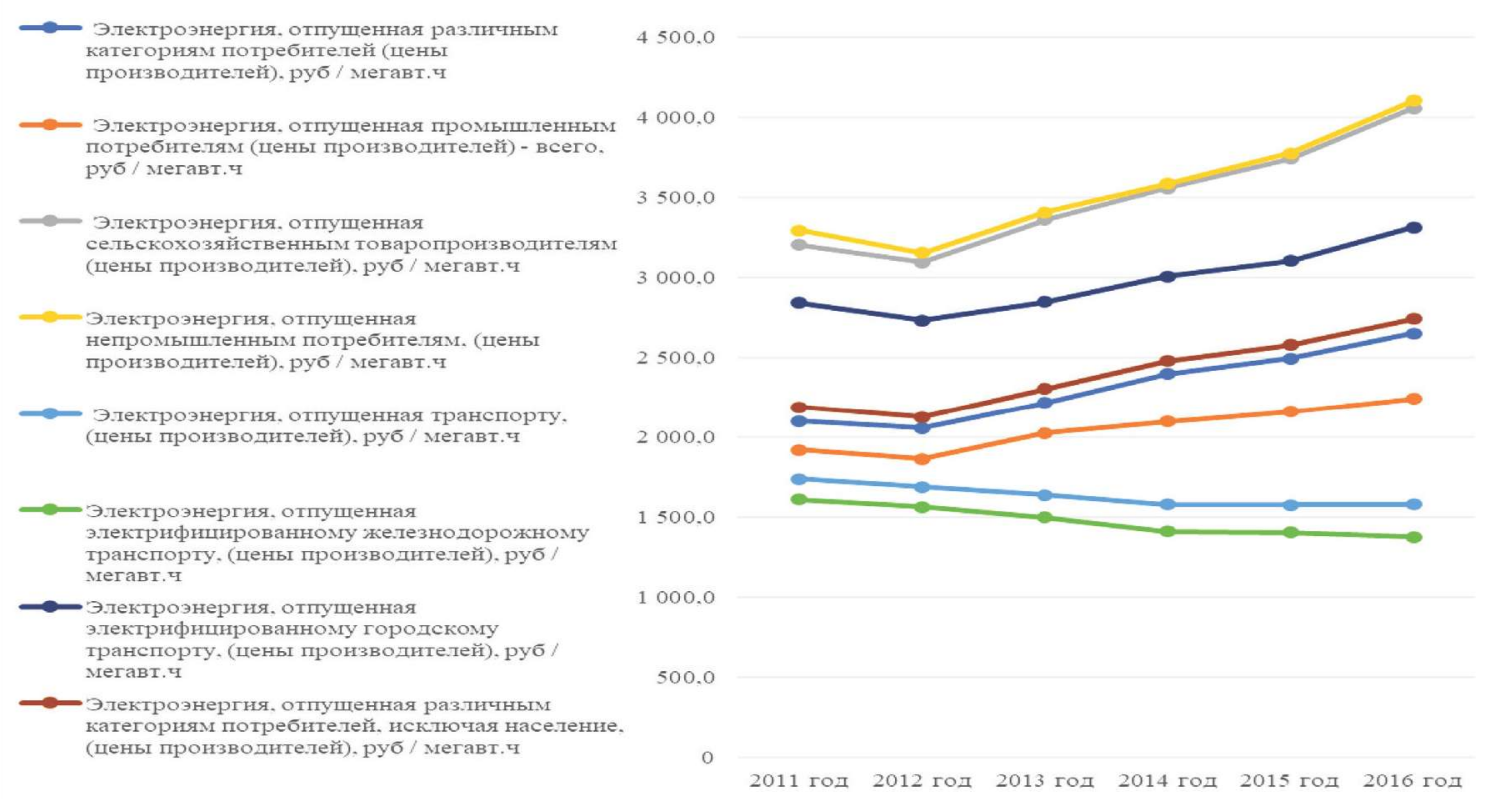

Рис. 4. Динамика цен на электроэнергию, отпущенную в разрезе категорий потребителей в РФ за 2011-2016 гг. (руб́./MВт час)

* Источник: данные FIRA 
Анализ данных, приведенных на рис. 4, показывает, что в течение 2011-2016 гг. происходил рост цен на электроэнергию, отпущенную практически для всех категорий потребителей, кроме категории «транспорт», за счет снижения отпускной цены электрифицированному железнодорожному транспорту.

Далее проведем более подробный анализ динамики цен на электроэнергию, отпущенную в разрезе категорий потребителей.

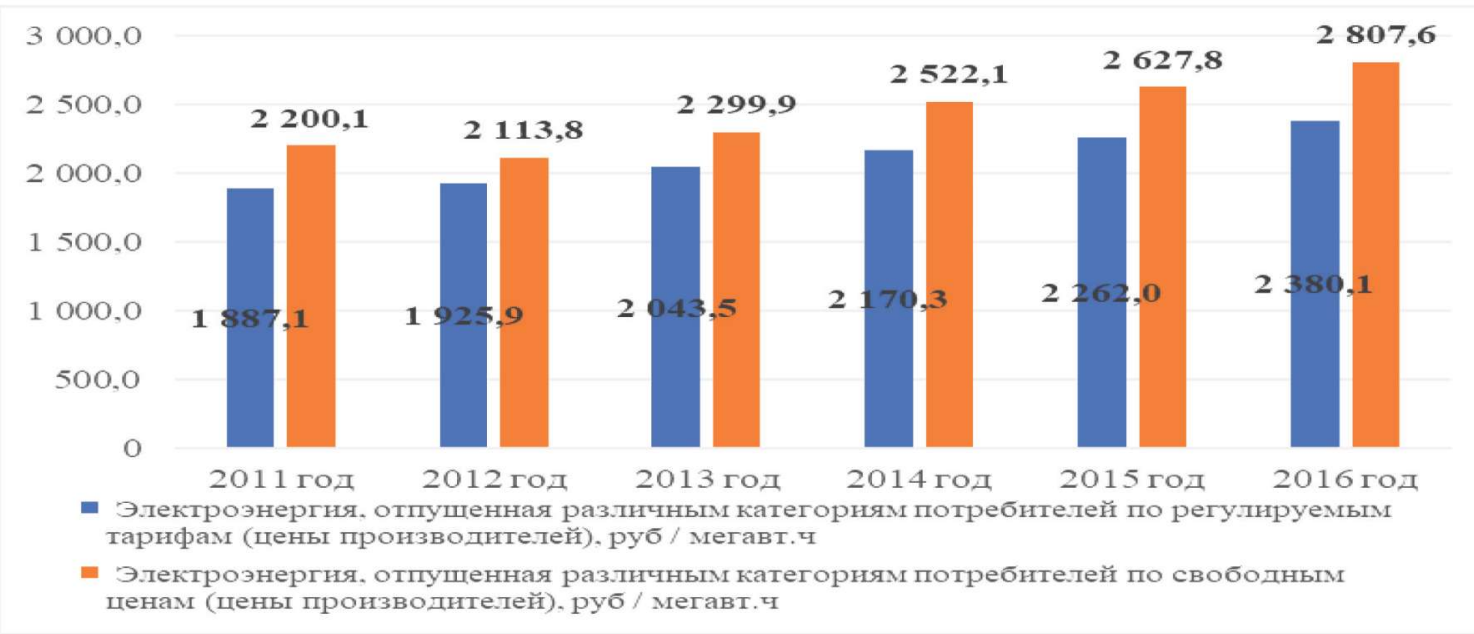

Рис. 5. Динамика цен на электроэнергию, отпущенную различным категориям потребителей в РФ за 2011-2016 гг. (руб./МВт час)

* Источник: данные FIRA

В 2016 году цена на электроэнергию, отпущенную различным категориям потребителей по регулируемым тарифам, составила 2380,1 руб./МВт час, увеличившись по сравнению с 2015 годом на 118,1 руб./МВт час. Увеличение данного показателя по сравнению с началом отчетного периода (2011 год) составило 493 руб./МВт час, или 26,1 \%, при этом для анализируемого показателя в течение всего рассматриваемого периода была характерна поступательная динамика роста.

Цена на электроэнергию, отпущенную различным категориям потребителей по свободным ценам, составила в 2016 году 2807,6 руб./МВт час, увеличившись по сравнению с 2015 годом на 179,8 руб./МВт час. Увеличение данного показателя по сравнению с началом отчетного периода (2011 год) составило 607,5 руб./МВт час, или 27,6 \%, при этом для анализируемого показателя также в течение всего рассматриваемого периода была характерна поступательная динамика роста (исключение составил только 2012 год, когда произошло незначительное снижение цены по сравнению с предыдущим периодом).

В 2016 году цена на электроэнергию, отпушенную промышленным потребителям по регулируемым тарифам, составила 2 051,1 руб./МВт час, уменьшившись по сравнению с 2015 годом на 21,6 руб./МВт час. При этом увеличение данного показателя по сравнению с началом отчетного периода (2011 год) составило 100 руб./МВт час, или всего 5,1%, при этом для анализируемого показателя в течение всего рассматриваемого периода была характерна волнообразная динамика роста.

Цена на электроэнергию, отпущенную промышленным потребителям по свободным ценам, составила в 2016 году 2 275,3 руб./МВт час, увеличившись по сравнению с 2015 годом на 98,3 руб./МВт час. Увеличение данного показателя по сравнению с началом отчетного периода (2011 год) составило 354,8 руб./МВт час, или 18,5 \%, при этом для анализируемого показателя также в течение всего рассматриваемого периода была характерна волнообразная динамика роста. 


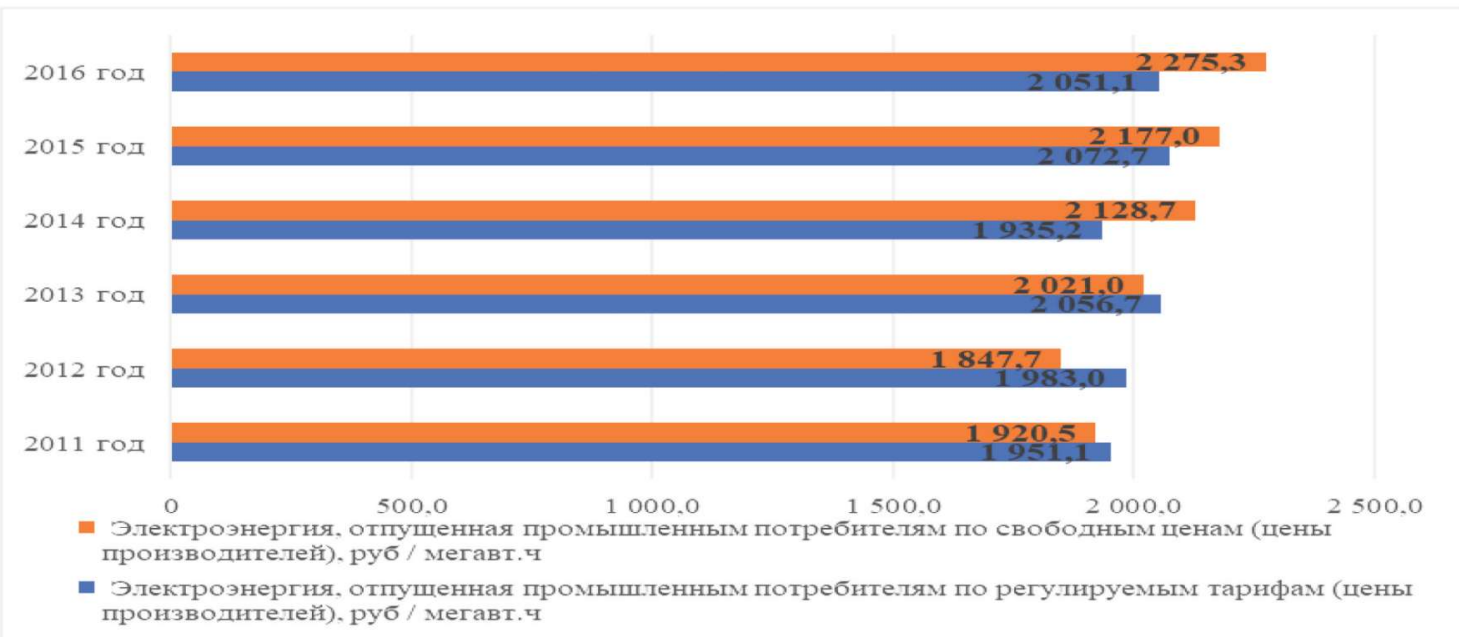

Рис. 6. Динамика цен на электроэнергию, отпущенную промышленным потребителям в РФ за 2011-2016 гг. (руб./МВт час)

* Источник: данные FIRA

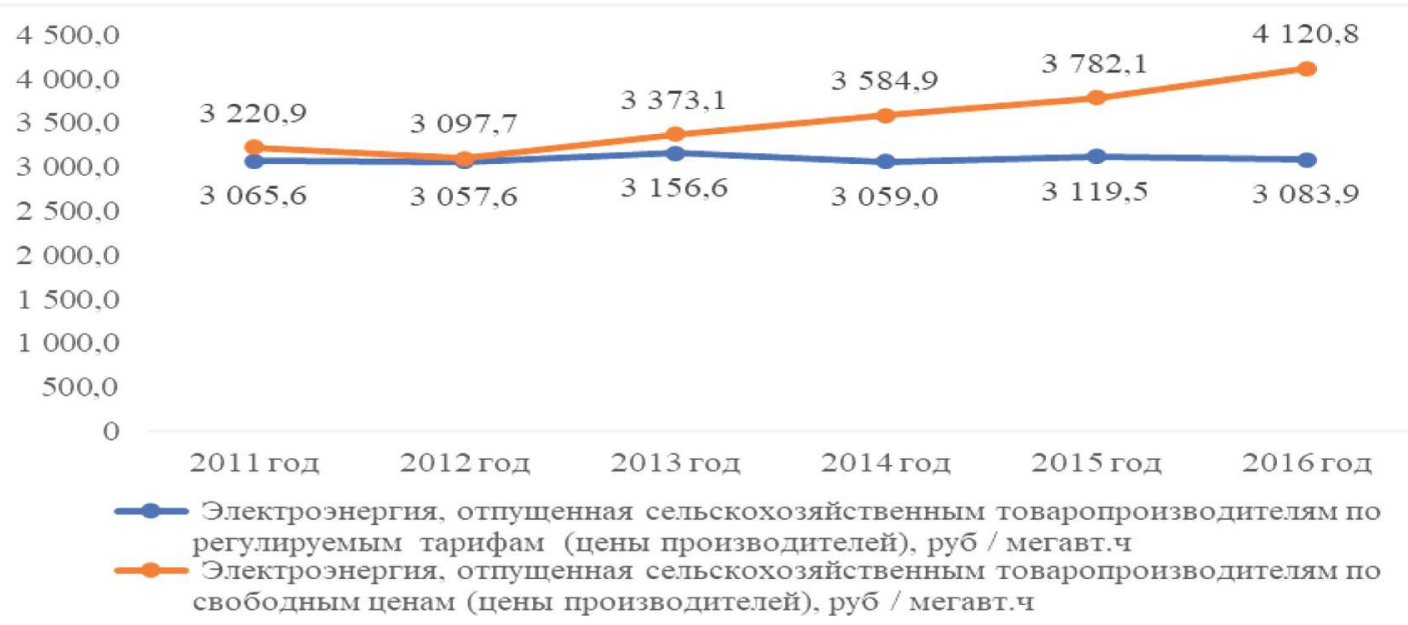

Рис. 7. Динамика цен на электроэнергию, отпущенную сельскохозяйственным товаропроизводителям в РФ за 2011-2016 гг. (руб./МВт час)

* Источник: данные FIRA

В 2016 году цена на электроэнергию, отпущенную сельскохозяйственным товаропроизводителям по регулируемым тарифам, составила 3083,9 руб./МВт час, уменьшившись по сравнению с 2015 годом на 35,6 руб./МВт час. При этом увеличение данного показателя по сравнению с началом отчетного периода (2011 год) составило 18,3 руб./МВт час, или всего 0,6 \%, при этом анализируемый показатель в течение всего рассматриваемого периода находился примерно на одном уровне.

Цена на электроэнергию, отпущенную сельскохозяйственным товаропроизводителям по свободным ценам, составила в 2016 году 4 120,8 руб./МВт час, увеличившись по сравнению с 2015 годом на 338,7 руб./МВт час. Увеличение данного показателя по сравнению с началом отчетного периода (2011 год) составило 899,8 руб./МВт час, или 27,9 \%, при этом для анализируемого показателя в течение всего рассматриваемого периода была характерна волнообразная динамика роста (исключение составил только 2012 год, когда произошло незначительное снижение цены по сравнению с предыдущим периодом). 


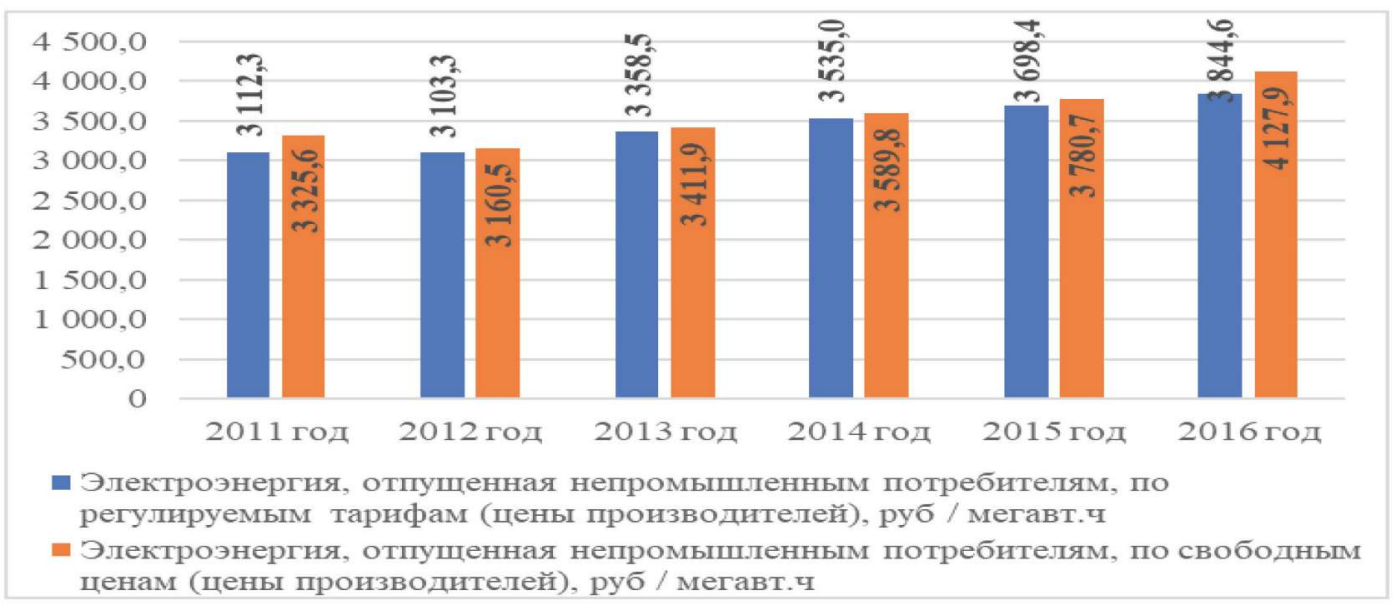

Рис. 8. Динамика цен на электроэнергию, отпущенную непромышленным потребителям в РФ за 2011-2016 гг. (руб./МВт час)

* Источник: данные FIRA

В 2016 году цена на электроэнергию, отпушенную непромышленным потребителям по регулируемым тарифам, составила 3844,6 руб./МВт час, увеличившись по сравнению с 2015 годом на 146,2 руб./МВт час. При этом увеличение данного показателя по сравнению с началом отчетного периода (2011 год) составило 732,3 руб./МВт час, или 23,5 \%, для анализируемого показателя в течение всего рассматриваемого периода была характерна волнообразная динамика роста.

Цена на электроэнергию, отпущенную непромышленным потребителям по свободным ценам, составила в 2016 году 4 127,9 руб./МВт час, увеличившись по сравнению с 2015 годом на 347,2 руб./МВт час. Увеличение данного показателя по сравнению с началом отчетного периода (2011 год) составило 802,4 руб./МВт час, или 24,1 \%, при этом для анализируемого показателя также в течение всего рассматриваемого периода была характерна волнообразная динамика роста.

В 2016 году цена на электроэнергию, отпущенную электрифицированному железнодорожному транспорту по регулируемым тарифам, составила 1 047,0 руб./МВт час, уменьшившись по сравнению с 2015 годом на 220,1 руб./МВт час. При этом уменьшение данного показателя по сравнению с началом отчетного периода (2011 год) составило 663,3 руб./МВт час, или $38,8 \%$, анализируемый показатель характеризовался динамикой роста до 2013 года и снижением в 2014-2016 гг.

Цена на электроэнергию, отпущенную электрифицированному железнодорожному транспорту по свободным ценам, составила в 2016 году 1 423,7 руб./МВт час, увеличившись по сравнению с 2015 годом на 0,8 руб./МВт час. Уменьшение данного показателя по сравнению с началом отчетного периода (2011 год) составило 169,0 руб./МВт час, или 10,6 \%, при этом для анализируемого показателя в течение всего рассматриваемого периода была характерна поступательная динамика снижения.

В 2016 году цена на электроэнергию, отпущенную электрифицированному городскому транспорту по регулируемым тарифам, составила 2214,3 руб./МВт час, увеличившись по сравнению с 2015 годом на 19,9 руб./МВт час. При этом уменьшение данного показателя по сравнению с началом отчетного периода (2011 год) составило 588,1 руб./МВт час, или $21 \%$, анализируемый показатель характеризовался снижением в период 2014-2015 гг. и незначительным увеличением в 2016 году.

Цена на электроэнергию, отпущенную электрифицированному городскому транспорту по свободным ценам, составила в 2016 году 3323,4 руб./МВт час, увеличившись по сравнению с 2015 годом на 213,0 руб./МВт час. Увеличение данного показателя по сравнению с началом отчетного периода (2011 год) составило 476,3 руб./МВт час, или 16,7 \%, при этом для анализируемого показателя в течение всего рассматриваемого периода была характерна поступательная динамика роста. 

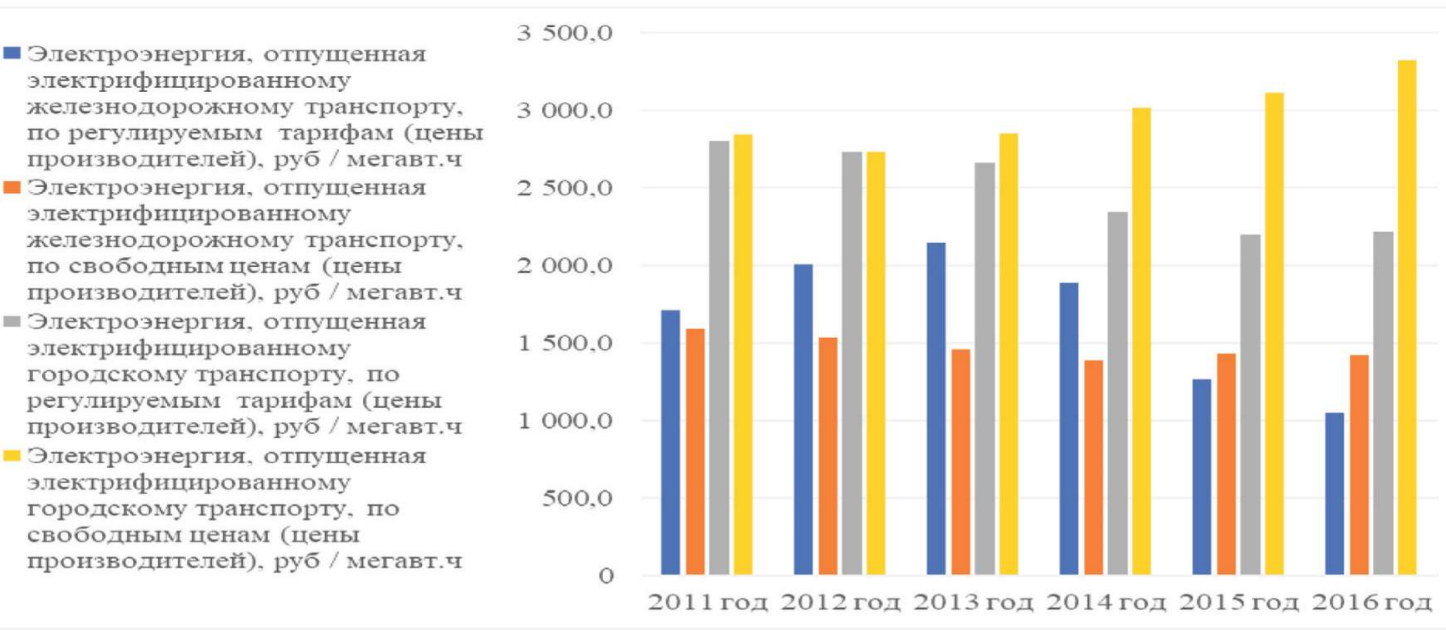

Рис. 9. Динамика цен на электроэнергию, отпущенную электрифицированному железнодорожному и городскому транспорту в РФ за 2011-2016 гг. (руб./МВт час)

* Источник: данные FIRA

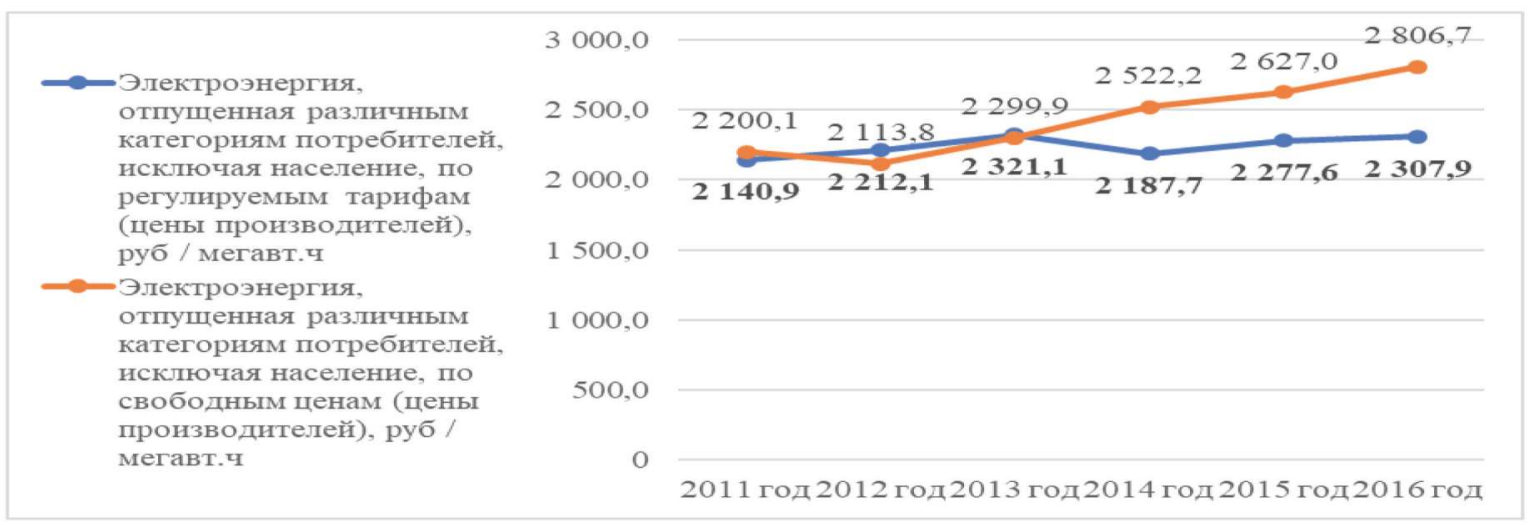

Рис. 10. Динамика цен на электроэнергию, отпущенную различным категориям потребителей, исключая население в РФ, за 2011-2016 гг. (руб./МВт час)

* Источник: данные FIRA

В 2016 году цена на электроэнергию, отпущенную различным категориям потребителей, исключая население, составила 2 307,9 руб./МВт час, увеличившись по сравнению с 2015 годом на 30,3 руб./МВт час. При этом увеличение данного показателя по сравнению с началом отчетного периода (2011 год) составило 167 руб./МВт час, или 7,8 \%, анализируемый показатель характеризовался ростом в 2011-2013 гг, незначительным снижением в 2014 году и последующим ростом в 2015-2016 гг.

Цена на электроэнергию, отпущенную различным категориям потребителей, исключая население, по свободным ценам, составила в 2016 году 2806,7 руб./МВт час, увеличившись по сравнению с 2015 годом на 179,7 руб./МВт час. Увеличение данного показателя по сравнению с началом отчетного периода (2011 год) составило 606,6 руб./МВт час, или 27,6 \%, при этом для анализируемого показателя в течение всего рассматриваемого периода была характерна поступательная динамика роста (за исключением 2012 года).

Таким образом, на основе проведенного выше анализа можно говорить о следующих общих тенденциях в области тарифного регулирования и свободного ценообразования в электроэнергетике как в целом по РФ, так и в федеральных округах: 
- отмечается прирост цен на электрическую мощность, проданную как по регулируемым тарифам, так и по свободным ценам, причем последние демонстрируют более быструю динамику роста;

- прирост цены на электрическую мощность, отпущенную по регулируемым ценам за 2011-2016 гг. составил 174,35 \%, а по свободным ценам - всего 18,29 \%;

- в течение 2011-2016 гг. был зафиксирован рост цен на электроэнергию, отпущенную для всех категорий потребителей, за исключением категории «электрифицированный железнодорожный транспорт».

Приоритетными государственными задачами в сфере совершенствования тарифной политики в области электроэнергетики в настоящее время являются:

- создание системы единых тарифов при технологическом подключении к сетям для всех регионов;

- определение эффективности реализации инвестиционных программ в валовой добавленной стоимости;

- совершенствование модели затрат сбытовых компаний с учетом новых подходов;

- развитие системы долгосрочных тарифов в отрасли.

\section{ЛИТЕРАТУРА И ИНТЕРНЕТ-РЕСУРСЫ}

1. Голомолзин А. Н. Новая тарифная политика: этапы реализации и стратегия // ФАС России. 06.12.2016 г.

2. Информационно-консалтинговая группа «Электрические сети в Системе» // Формирование тарифов на электроэнергию. 02.06.2017 год. URL: http://electricalnet.ru/blog/formirovanie-tarifov-naelektroenergiu

3. Линдер Н. В., Володин Ю. В. Тарифная политика и перекрестное субссидирование в электро- и теплоэнергетике // Стратегии бизнеса: электронный научно-экономический журнал. 2017. № 1(33). С. 37-47.

4. Минэнерго России. Годовое общее собрание членов Ассоциации «НП Совет рынка» за 2016 год/Сниккарс П. Н. Директор департамента развития электроэнергетики Минэнерго России. М., 2017. URL: https://lk.np-sr.ru/sites/default/files/sr_pages/SR_0V055464/2017-05-18-minenergo-rossii-gosa-soveta-rynka.pdf

5. Новак А. В. Итоги работы Минэнерго России и основные результаты функционирования ТЭК в 2012-2017 гг. Задачи на среднесрочную перспективу. M., 2018. 6 апреля. URL: https://minenergo.gov. ru/node/11279.

6. Прогноз социально-экономического развития Российской Федерации на 2018 год и на плановый период 2019 и 2020 годов. URL: http://www.consultant.ru/document/cons_doc_LAW_282738/

7. Особенности тарифного регулирования в электроэнергетике и ЖКХ: доклад / Федеральная антимонопольная служба России. 2016. Февраль.

8. Тарифное регулирование 2018 и перспективные направления: доклад / Федеральная антимонопольная служба России. 05.03.2018.

\section{REFERENCES AND INTERNET RESOURCES}

1. Golomolzin A. N. Novaya tarifnaya politika: ehtapy realizacii i strategiya (The new tariff policy: the stages of implementation and strategy) // FAS Rossii. 06.12.2016 g

2. Informacionno-konsaltingovaya gruppa «EHlektricheskie seti v Sisteme» (Information and consulting group «Electrical networks in the System») // Formirovanie tarifov na ehlektroehnergiyu. 02.06.2017 god. URL: http://electricalnet.ru/blog/formirovanie-tarifov-na-elektroenergiu.

3. Linder N. V., Volodin YU. V. Tarifnaya politika i perekrestnoe subsidirovanie $v$ ehlektro- i teploehnergetike (Tariff policy and cross-subsidies in electricity and heat) // Strategii biznesa: ehlektronnyj nauchnoehkonomicheskij zhurnal. 2017. № 1(33). P. 37-47. 
4. Minehnergo Rossii / Godovoe Obshchee sobranie CHlenov Associacii «NP Sovet rynka» za 2016 god Ministry Of Energy (Annual General meeting of members of the Association «NP market Council» for 2016)/ Snikkars P. N. Direktor departamenta razvitiya ehlektroehnergetiki Minehnergo Rossii. M., 2017. URL: https://lk.np-sr.ru/sites/default/files/sr_pages/SR_0V055464/2017-05-18-minenergo-rossii-gosa-soveta-rynka.pdf

5. Novak A. V. Itogi raboty Minehnergo Rossii i osnovnye rezul'taty funkcionirovaniya TEHK v 2012-2017 gg. Zadachi na srednesrochnuyu perspektivu (The results of the Ministry of energy of Russia and the main results of the fuel and energy sector in 2012-2017. Objectives for the medium term). M., 2018. 6 aprelya. URL: https://minenergo.gov.ru/node/11279

6. Prognoz social'no-ehkonomicheskogo razvitiya Rossijskoj Federacii na 2018 god i na planovyj period 2019 i 2020 godov (Forecast of socio-economic development of the Russian Federation for 2018 and the planning period 2019 and 2020). URL: http://www.consultant.ru/document/cons_doc_LAW_282738/

7. Osobennosti tarifnogo regulirovaniya $v$ ehlektroehnergetike i ZHKKH (Peculiarities of tariff regulation in the electric power industry and housing and communal services): doklad / Federal'naya antimonopol'naya sluzhba Rossii. 2016. fevral'.

8. Tarifnoe regulirovanie 2018 i perspektivnye napravleniya (Tariff regulation 2018 and future directions): doklad / Federal'naya antimonopol'naya sluzhba Rossii. 05.03.2018.

\section{СВЕДЕНИЯ ОБ АВТОРАХ}

Рыкова Инна Николаевна, доктор экономических наук, руководитель Центра отраслевой экономики Федерального государственного бюджетного учреждения «Научно-исследовательский финансовый институт» Министерства финансов Российской Федерации, г. Москва. E-mail: rycova@yandex.ru

Табуров Денис Юрьевич, кандидат технических наук, эксперт Центра отраслевой экономики Федерального государственного бюджетного учреждения «Научно-исследовательский финансовый институт» Министерства финансов Российской Федерации, г. Москва. E-mail: taburov@narod.ru

\section{INFORMATION ABOUT AUTHORS}

Rykova Inna, Doctor of Economics, Head of the Sectorial Economy Center Federal state budgetary institution «Scientific research Institute of Finance» of the Ministry of Finance of the Russian Federation, Moscow. E-mail: rycova $a y a n d e x . r u$

Taburov Denis, PHD (Engineering), expert researcher of the Sectorial Economy Center Federal state budgetary institution «Scientific research Institute of Finance» of the Ministry of Finance of the Russian Federation, Moscow. E-mail: taburov@narod.ru 